\title{
ETNOGEOMORFOLOGIA SERTANEJA: ESTUDO DOS CONHECIMENTOS TRADICIONAIS SOBRE PROCESSOS MORFOESCULTURADORES NO SÍTIO CACIMBAS - JARDIM/CE
}

\author{
Maria Rayssa Vieira Antunes ${ }^{(\mathrm{a})}$, Francisca Ranielly de Brito Macêdo ${ }^{(\mathrm{b})}$, Simone Cardoso \\ Ribeiro $^{(\mathrm{c})}$
}

(a) Estudante de Licenciatura em Geografia, Bolsista de Iniciação Científica - PIBIC/URCA, rayssa.antunes@yahoo.com

(b) Estudante de Licenciatura em Geografia, Bolsista de Iniciação Científica - PIBIC/URCA - URCA, f.raniellydbm@gmail.com

(c) Orientadora - Professora Associada - DEGEO, Doutora em Geografia, URCA, simone.ribeiro@urca.br

\section{EIXO: SISTEMAS GEOMORFOLÓGICOS: ESTRUTURA, DINÂMICA E PROCESSOS}

\begin{abstract}
Resumo
Aplicando os conceitos e metodologias de Etnogeomorfologia Sertaneja, a pesquisa busca identificar a percepção ambiental e os saberes vernaculares sobre formas e processos geomórficos, dos produtores rurais sertanejos e a ultilizção destes conhecimentos no uso/manejo dos solos voltados para agropecuária no município de Jardim/CE. Os procedimentos metodologicosforam: levantamento de dados bibliográficos, cartográficos e elaboração de roteiro de entrevistas; pesquisa de campo, entrevistas com os produtores rurais; e análise dos dados coletados. Das formas de relevo identificadas, destacam-se as terras "altas", "baixas", "carrasco"," chapada", "Serra" e "lombada". Quanto às cicatrizes erosivas, a denominação mais utilizada para denominar voçorocas e ravinas é "grota", enquanto micro ravinas são nomeadas como "vala". Dos tipos de solos indicados pelos agricultores, foram mencionados e descritos: "terra vermelha", "terra preta", e "terra ariúsca". A pesquisa produz uma análise dos saberes tradicionais com um diálogo entre população e academia.
\end{abstract}

Palavras chave: Etnoconhecimento. Comunidades Tradicionais. Cariri cearense.

\section{Introdução}

O relevo é um elemento que constitui o cenário da paisagem, e seu conhecimento é essencial para entender a dinâmica ambiental, bem como, a organização espacial das sociedades. A geomorfologia é a ciência voltada para o estudo dos agentes responsáveis pela dinâmica do relevo. Levando em consideração que os conhecimentos tradicionais são estudados pela ciência, surge no âmbito acadêmico a Etnogeomorfologia, que com os conceitos de Ribeiro (2012), traz a visão dos agricultores e a sua relação com o relevo.

As comunidades tradicionais possuem cultura própria e, segundo COSTA (2011), são chamadas de etnocidades ecológicas ou povos de ecossistema, pois, retiram o seu sustento do meio em que vivem, 


\section{OS DESAFIOS DA GEOGRAFIA FÍSICA NA FRONTEIRA DO CONHECIMENTO \\ Instituto de Geociências - Unicamp \\ Campinas - SP \\ 28 de Junho à 02 de Julho de 2017}

dependem da agricultura de subsistência. Os grupos que deriva o seus sustento do ambiente em que vivem são chamados de etnocidades ecológicas segundo COSTA (2011).

O termo "Comunidades tradicionais" é um conceito mais utilizado no Brasil para descrever grupos rurais ligados aos ambientes naturais e que dele dependem diretamente para sobreviver. Como ressalta COSTA (2011, pág 111) em seu livro Cultura é Natureza "Pode-se dizer que são tradicionais os povos que mantem um modo de vida intimamente relacionado ao ambiente onde vivem, dependendo diretamente dele".

Vale salientar que o fato do uso e manejo do ambiente faz com que acelere os processos erosivos, principalmente em áreas de fragilidade ambiental como é o caso das regiões semiáridas. As relações do homem/ natureza ganham mais fomento quando atreladas a cultura, o fato de tentar resgatar esse conhecimento tradicional intrínseco das taxonomias é manter a cultura viva, bem como, aproximando e relacionando com o conhecimento cientifico.

O presente trabalho tem por objetivo identificar como os produtores rurais familiares do Sítio Cacimbas, no município de Jardim/CE, compreendem as formas e os processos de modelagem do relevo e como fazem uso desses saberes para o manejo do espaço.

\section{Material e Métodos}

A priore foi feito o levvantamento bibliografico relacionado à Geomorfologia e Etnociências, voltado mais para a Etnopedologia, Etnogeomorfologia e Etnoecologia. A metodologia foi baseada nos estudos de Ribeiro (2012), que trabalha com a etnogeomorfologia sertaneja da sub-bacia do rio Salgado/CE. Em seguida, foi realizada a produção de perfis topograficos elaborados pelo 3D Path Profile/Line of Sight do software Global Mapper 6, usando como base as imagens SRTM ( MIRANDA, 2005)

Em campo foram realizadas entrevistas co os sertanejos/agricultores no núcleo familiar do Sítio Cacimba localizado no município de Jardim/CE. A escolha dos entrevistados foi feita por amostragem qualitativa, pelo método de indicação (Snowball Sampling), onde um agricultor já entrevistado indicava outro(a); com o decorrer das entrevistas notou-se que as respostas estavam repetindo-se, bem como os nomes de agricultores indicados para entrevista - sendo esse o limite qualitativo para a coleta de dados segundo esse método.

Foram entrevistados nove agricultores, sendo seis do sexo masculino e três do sexo feminino, com faixa etária que varia entre 25 e 70 anos de idade, e somente um dosentrevistados possui o Ensino Médio completo, o restante não chegou a concluir o Ensino Fundamental.

Foi utilizada como ferramenta de auxilio para as entrevistas imagens de erosões e cicatrizes em diversos estágios do processo, o que facilitou a identificação dos aspectos e feições da erosão sem haver 
XVII Simpósio Brasileiro

de Geografia Fisica Aplicada

I Congresso Nacional

de Geografia Física
OS DESAFIOS DA GEOGRAFIA FÍSICA NA FRONTEIRA DO CONHECIMENTO

Instituto de Geociências - Unicamp

Campinas - SP

28 de Junho à 02 de Julho de 2017

interferência em sua taxonomia. Depois de identificadas essas erosões, era perguntado ao entrevistado qual nomenclatura o mesmo utilizava para nomeá-las e se o mesmo sabia quais as causas desses fenômenos.

Com a conclusão das entrevistas, foi realizada uma tabela com as respostas a cerca dos conhecimentos vernaculares relacionado aos processos que contemplam a etnogeomorfologia juntamente com os conceitos científicos e, por fim, foi feita a comparação desses conhecimentos.

\section{Resultado e Discussões}

As técnicas aplicadas no manejo do solo na comunidade ainda são tradicionais, a mecanização é algo pouco introduzido, com base nos entrevistados. Somente três dos entrevistados são do município de Jardim/CE, sendo que apenas um deles nasceu e vive ainda hoje no sitio Cacimbas. Os demais entrevistados são de cidades ou estados vizinhos, alegam ter ido para a comunidade para trabalhar na lavoura porque a família comprou terras na região.

Das formas de relevo descritas pelos agricultores, podemos destacar referente as partes mais altas e aplainadas os etnoconhecimentos de "chapada" e "Serra", como ressalta um entrevistado: "o relevo aqui é pouco elevado porque serra é mais plana mesmo”. As áreas que tem um declive acentuado são chamadas de "lombadas", que sempre são seguidas de uma topografia mais rebaixada que é chamada de "baixa" ou "terras baixa" como é destacado na fala de um entrevistado: "Tem a parte baixa que é onde moreia, e tem parte alta que chama de chapada." .

Das unidades etnogeomorfológicas que foram indicadas pelos produtores estão representadas pelo meio de perfis topográficos, indicados pelas figuras 1e 2 .

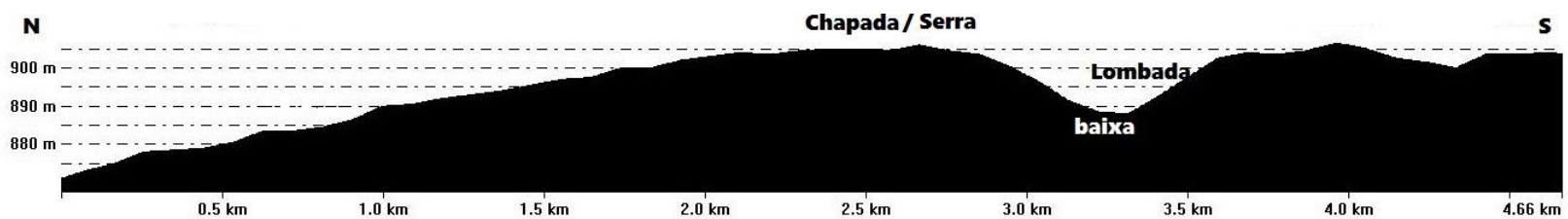

Figura 1- Perfil topográfico das unidades etnogeomorfológicas indicadas pelos produtores do Sítio Cacimba. Fonte:

autoras, 2017

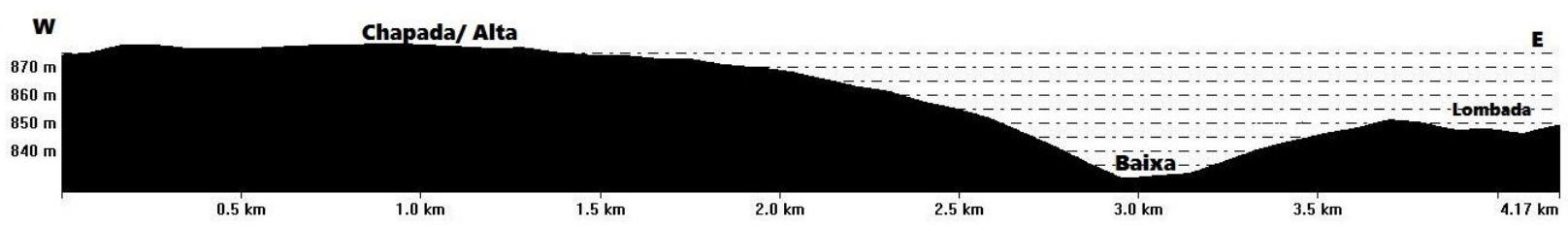

Figura 2- Perfil topográfico das unidades etnogeomorfológicas indicadas pelos produtores do Sítio Cacimba. Fonte: autoras, 2017 
Os tipos de solos indicados pelos agricultores foram mencionados, : "barro argiloso", "terra preta" ou "barro preto" e "terra branca" ou "terra ariúsca", "terra vermelha” ou "terra de carrasco". Referente ao solo que tem melhor estrutura para se plantar alguns consideram que a "terra preta" , "terra de areia" " "barro argiloso" é melhor "Terra preta é boa pra plantar e a terra branca rejeito porque não dá”.

Os produtores preferem cultivar em terras que tenham uma coloração mais escura ou em terras onde tenha a presença de areia, alegam que tais terras são mais indicadas para o plantio. Referente aos locais onde estes solos estão presentes um entrevistado ressalta “O baixo é melhor para plantar, a vegetação é sempre verdinha e a terra mais dura e com areia".

Dos processos erosivos que atuam no relevo, destacam-se a erosão que acarreta o transporte e deposição de sedimentos. Estes foram identificados com uma maior facilidade pelos entrevistados . Os etnoconhecimentos referentes a esses processos tem por denominação mais comumente utilizada para suas cicatrizes são; "grota”, “cratera” , vala” que são referentes as voçorocas e ravinas, respectivamente, enquanto as micro ravinas são chamadas de "lagoinha d'água" ou " bojo das formigas". Esses processos e a suas formações, segundo os etnoconhecimentos colhidos, são decorrentes da ação das chuvas, e estão relacionados com a retirada da vegetação.

Quanto aos movimentos gravitacionais de massa, foram descriminados por dois entrevistados, que os denominaram de "deslizamento" e identificaram que se localizam em relevos de declive acentuado .Com relação ao uso e manejo dos solos, apenas três dos entrevistados alegam fazer queimadas em suas “ roças", os mesmos denominam tal atividade de "broca", que é a retirada da vegetação em seguida faz a " coivara" que consiste na junção do material e em seguida faz a queimada da área.

Os agricultores alegam que a produção diminui com o passar dos anos sem adubar a terra, e as estratégias utilizadas por eles consistem na adubagem e no pousio - deixar a terra descansar por alguns anos. Afirmam que dá para fazer uso da terra dois anos seguidos sem adubar e depois deixa a vegetação crescer como ressalta um dos entrevistados: "Sem adubar ela só aguenta dois anos e deixa mais dois anos descansando até matar”.

Observou-se que as respostas das entrevistas foram um tanto semelhantes, referentes aos saberes sobre os agentes exógenos que modelam o relevo e o uso e manejo do espaço, e os seus métodos são utilizados de acordo com a necessidade das áreas que exploram. 


\section{Considerações Finais}

Com os dados obtidos foi possivel conluir que o agricultor do semiárido nordestino através das experiências na área em que vive e explora, mostra que a Etnogeomorfologia como um ramo das Etnociências pode assumir um papel de suma importância, buscando um melhor ordenamento local tomando como base as potencialidades, fragilidades e suas práticas no uso e manejo do espaço que foram identificadas pelos produtores.

\section{Agradecimentos}

Agradeçemos à Universidade Regional do Cariri/URCA pelo apoio financeiro através da Bolsa de Iniciação Cientifica - URCA, à Dra. Simone Cardoso Ribeiro por todo incentivo e orientação no decorrer da pesquisa, a todos os colegas que compõe o Laboratório de Geomorfologia e Pedologia GeoPed/URCA e que nos ajudaram na pesquisa como também aos agricultores do sítio Cacimbas, $\mathrm{Jardim} / \mathrm{CE}$ que se disponibilizaram em responder às entrevistas.

\section{Bibliografia}

COSTA. L. M. Cultura e natureza. Editora Garamond, 2011.

MIRANDA, E. E. de; (Coord.). Brasil em Relevo. Campinas: Embrapa Monitoramento por Satélite, 2005. Disponível em: <http://www.relevobr.cnpm.embrapa.br>. Acesso em: 12 Dez. 2016

RIBEIRO, S.C. Etnogeomorfologia Sertaneja: proposta metodológica para a classificação das paisagens da sub-bacia do rio Salgado/CE. Rio de Janeiro: UFRJ/PPGG, 2012. 278 p.(Tese de Doutorado) 